The

\title{
Effect of feed supplementation through turmeric and Tulsi leaves on growth of broiler chicks in deep litter system
}

U.K. Shukla, Deepak Pandey and Shri Kant

Author for Corresponding -

\section{Shri Kant}

Livestock Production and

Management Unit, Department

of Natural Resource

Management, Faculty of

Agriculture, Mahatma Gandhi

Chitrakoot Gramodaya

Vishwavidyalaya, Chitrakoot,

Satna (M.P.) India

Email: shrikantag695@gmail.

com
ABSTRACT...... The experiment was conducted at the livestock production and management unit, faculty of agriculture. MGCGV Chitrakoot - Satna ( M.P.). To complete the research work following steps were followed. Day old 75 broiler chicks (DOC) of same hatch were produced and reared in of Deep litter system. The chicks were weighed, leg banded and distributed randomly into five groups of 15 chicks each as treatment. Chicks of each treatment were further divided into three sub groups of five chicks in each in Randomized Block Design (RBD). Chicks of each sub group were accommodated comfortably in deep letter system providing $1 \mathrm{sq}$. ft./ chick. Chicks were fed standard starter ration upto 3 weeks age (1 to 21 days) and then broiler finisher ration upto 3-4 weeks (22-28 days). An experiment was conducted with DOC to 75 broilers chicks divided into five groups $T_{0}, T_{1}, T_{2}$ and $T_{4}$ which were supplemented with turmeric and Tulsi leaves powder@1.0g, 2.0g, 3.0g and 4.0g/kg of broiler ration, respectively. Weekly observations were recorded for live body weight, weekly gain in weight, weekly feed consumption and feed conversion of broiler for four weeks. Based on the results of the experiment, it may be concluded that feed supplementation with turmeric (Curcuma longa) powder influenced the body weight, gain in body weight, feed intake and feed efficiency of broiler chicks. Based on the result of the experiment, it may be concluded that feed supplementation with turmeric + Tulsi leaves powder influenced body weight, gain in body weight, feed intake and feed efficiency of broiler chicks. Based on feed intake and feed efficiency, the best performance of broilers was obtained with feed supplementation of $3 \mathrm{~g}$ turmeric $+3 \mathrm{~g}$ Tulsi powder per $\mathrm{kg}$ of standard ration $\left(\mathrm{T}_{3}\right)$, followed by $4 \mathrm{~g}$ turmeric $+4 \mathrm{~g}$ Tulsi leaf powder $\left(\mathrm{T}_{4}\right)$. Treatment $\mathrm{T}_{3}$ was economically superior over all other treatments and control.

KEY WORDS...... Broiler chicks, Growth performance, Turmeric, Tulsi leaves powder

HOW TO CITE THIS ARTICLE - Shukla, U.K., Pandey, Deepak and Kant, Shri (2020). Effect of feed supplementation through turmeric and Tulsi leaves on growth of broiler chicks in deep litter system. Asian J. Animal Sci., 15(1): 59-65.DOI:10.15740/HAS/TAJAS/15.2/59-65.Copyright@2020: HindAgriHorticultural Society.

ARTICLE CHRONICLE - Received : 25.07.2020; Revised : 15.10.2020; Accepted : 10.11.2020 